\title{
BMJ Open Prevalence and distribution of hypertension and related risk factors in Jilin Province, China 2015: a cross- sectional study
}

\author{
Junduo Wu, ${ }^{1}$ Tianyi Li, ${ }^{1}$ Xianjing Song, ${ }^{1}$ Wei Sun, ${ }^{1}$ Yangyu Zhang, ${ }^{2}$ Yingyu Liu, ${ }^{2}$ \\ Longbo Li, ${ }^{1}$ Yunpeng Yu, ${ }^{1}$ Yihang Liu, ${ }^{1}$ Chao Qi, ${ }^{1}$ Bin Liu ${ }^{1}$
}

To cite: Wu J, Li T, Song X, et al. Prevalence and distribution of hypertension and related risk factors in Jilin Province, China 2015: a crosssectional study. BMJ Open 2018;8:e020126. doi:10.1136/ bmjopen-2017-020126

- Prepublication history and additional material for this paper are available online. To view these files, please visit the journal online (http://dx.doi. org/10.1136/bmjopen-2017020126).

Received 17 October 2017 Revised 15 February 2018 Accepted 21 February 2018
Check for updates

${ }^{1}$ Department of Cardiology, The Second Hospital of Jilin University, Changchun, China ${ }^{2}$ Department of Epidemiology and Biostatistics, School of Public Health, Jilin University, Changchun, China

Correspondence to

Dr Bin Liu;

liubin3333@vip.sina.com

\section{ABSTRACT}

Objective This study aimed to investigate the prevalence and distribution of hypertension and its related factors in Jilin province, China.

Design A cross-sectional study in four cities and four rural counties in Jilin as part of a national Chinese study.

Participants and setting A total of 15206 participants who were $\geq 15$ years old and were selected using a stratified multistage random sampling method.

Main outcome measures The prevalence of hypertension.

Results The prevalence of hypertension in Jilin province was $24.7 \%$. Moreover, the prevalence of hypertension increased with age in both sexes, and was higher in men than in women. The modifiable factors that were associated with hypertension were body mass index, smoking and alcohol drinking. The risk factors identified are similar to those in southern China, except smoking, which has no association with hypertension prevalence in the South.

Conclusions Age, sex, body mass index, smoking and alcohol drinking were risk factors of hypertension. Control of these related risk factors, especially smoking, may be helpful in the treatment and management of hypertension in Jilin province.

\section{INTRODUCTION}

A recent WHO report indicated that cardiovascular diseases (CVD) are at the top of the list of the four prioritised non-communicable diseases worldwide and that they require immediate global action plans for prevention and control. ${ }^{1}$ Hypertension is a leading cause of cardiovascular diseases and related deaths worldwide. ${ }^{23}$ It is estimated that the global economic burden related to hypertension could be as high as US $\$ 370$ billion. ${ }^{4}$

In the People's Republic of China, the prevalence of hypertension has been increasing dramatically from $5.1 \%$ in 1959 to $7.7 \%$ in $1979,13.6 \%$ in 1991 and $18.8 \%$ in $2002 .{ }^{56}$ Furthermore, there is a disproportionately higher hypertension rate reported among
Strengths and limitations of this study

- This cross-sectional population-based study evaluated a large representative sample of individuals from four cities and four rural counties in Jilin province.

- A large sample of participants allowed for subgroups analysis of related factors.

- The causality of the relationships between hypertension and the related factors cannot be confirmed.

- Data were not collected regarding physical activity, salt intake and blood lipid levels.

people living in northern China. ${ }^{78}$ There are about 109.4 million people in the northeastern China. The province of Jilin is located in the northeast of China, with a population of approximately 27.5 million according to the National Bureau of Statistics. Similar to other northern provinces, Jilin has a longer winter season than southern China, and, limited by this environment, the lifestyle of the people is different from the other parts of the country.

An in-depth analysis of data from Jilin province regarding hypertension and its risk factors would improve our understanding of the differential reasons for hypertension in the North. Moreover, the analysis would assist in the development of locally effective intervention and control strategies for this preventable disease. Thus, the objectives of this study were to estimate the prevalence of hypertension in Jilin province and to explore potential risk factors that are associated with hypertension in the province. This will provide information for making recommendations on the prevention and control of hypertension in the northern region of China. 


\section{METHODS}

\section{Study population}

This cross-sectional study was conducted between July 2014 and December 2015 as a part of national China study. A four-stage, stratified sampling method was used to select participants who were aged 15 years and older from the general population of Jilin province, China. First, four cities from the urban areas and four counties from rural areas were selected using a probability proportional to size. Then two districts or two townships were selected in each city or county using simple random sampling (SRS). Next, in each district and township, three communities or villages were chosen respectively using SRS. Finally, participants stratified by sex ( $50 \%$ men and $50 \%$ women) and age (aged 15-24, 25-34, 35-44, 45-54, 55-64, 65-74, $65-74, \geq 75$ years) were chosen using SRS according to the national population composition. Participants were chosen from the list provided by the local government registers of households. ${ }^{9}$

Based on a design effect of 2.5 and assuming a prevalence of hypertension of $17.7 \%$ among the population aged 15 years and older, an estimated sample size of 15200 participants was needed to ensure that the bound on the error of estimation (ie, width of the $95 \% \mathrm{CI}$ ) for the prevalence in the entire population and subpopulation defined by age and sex were less than $0.4 \%$ and $1.8 \%$, respectively. ${ }^{9}$ As a result, a total of 15206 participants living in Jilin province over 6 months and aged 15 years and older were randomly selected to participate in the survey.

\section{Measurement}

The survey involved a questionnaire interview and physical examination. The standardised questionnaire was developed by the national coordinating centre of Fuwai Hospital (Beijing, China) and included questions on demographic characters, health behaviours and physical activities. The questionnaire was completed by the participants in a face-to-face interview with a trained staff.

The physical examination evaluated blood pressure (BP), body weight and height. BP was measured at the right arm supported at the heart level after participants resting for $5 \mathrm{~min}$, using the Omron HBP-1300 Professional Portable Blood Pressure Monitor (OMRON, Japan). BP was measured three times, with $30 \mathrm{~s}$ between each measurement. The average of three readings was used for further analysis. ${ }^{10}$ Body weight, basal metabolism (BM), body fat percentage (BFP) and visceral fat index (VFI) were measured without heavy clothing using an OMRON body fat and weight measurement device (Vbody HBF-371, OMRON, Japan). Height was measured without shoes using a standard right-angle device and a fixed measurement tape (to the nearest $0.5 \mathrm{~cm}$ ).

\section{Definitions}

Hypertension was defined as systolic BP (SBP) $\geq 140 \mathrm{~mm} \mathrm{Hg}$ or diastolic BP (DBP) $\geq 90 \mathrm{~mm} \mathrm{Hg}$ or self-reported use of antihypertensive medication. ${ }^{11}$ Body mass index (BMI) was calculated as $\mathrm{kg} / \mathrm{m}^{2}$. Overweight was defined as BMI $25-30 \mathrm{~kg} / \mathrm{m}^{2}$, and obesity was defined as $\mathrm{BMI}>30 \mathrm{~kg} / \mathrm{m}^{2}$.

\section{Statistical analysis}

Data were entered and validated using EpidataV.3.0 software. ${ }^{12}$ All estimates and analyses were weighted to represent the population in Jilin Province aged 15 years or older. The weights were calculated based on the 2010 Jilin province population census data, as well as the sampling age, sex and geographic subgroups. Continuous data were presented as mean $\pm \mathrm{SD}$ or mean with $95 \%$ CI, and differences between groups were compared using the t-est. Categorical data were presented as frequency, rate and 95\% CI and the prevalence between different groups was compared using the corrected Rao-Scott $\chi^{2}$ test. Logistic regression analysis was conducted assessing the relationship of hypertension with age, sex, obesity, smoking and alcohol drinking adjusted for demographic factors that have been included in similar studies, including sex, region, age, education level, employment status, marital status, BMI and family history of hypertension. All analyses were conducted using SPSSV.18.0 software. ${ }^{13}$

\section{RESULTS}

\section{Distribution of participants}

A total of 14956 participants from 15206 eligible participants (6946men and 8010 women; aged 15-97 years) completed the survey and were included in the statistical analysis. The percentages of male and female respondents were $50.63 \%$ and $49.37 \%$, respectively. The non-responders $(1.6 \%)$ were mainly young people, and their non-response was likely attributable to their busy work schedule.

\section{Characteristics of participants}

The average age of the participants was 45.5 years, with the average age for men being $45.6 \pm 19.6$ years and for women $45.5 \pm 18.9$ years. There was no statistically significant difference in age between the sexes $(\mathrm{P}=0.92)$. The distribution of participants by age and sex are shown in table 1 . The participants had average values of $24.01 \pm 3.67 \mathrm{~kg} / \mathrm{m}^{2}$ for BMI, $1,397.47 \pm 244.15$ for BM, $26.20 \pm 8.4$ for BFP and $8.54 \pm 4.99$ for VFI. The mean SBP was $128.92 \pm 17.97 \mathrm{~mm} \mathrm{Hg}$, and the mean DBP was $76.81 \pm 10.36 \mathrm{~mm} \mathrm{Hg}$. These physical characteristics by age and sex are shown in online supplementary table 1 . All these characters were statistically significantly different between men and women $(\mathrm{p}<0.01)$. In particular, male participants had higher BM and VFI values than female participants in all age groups (figure $1 \mathrm{~A}$ and $\mathrm{B}$ ), while female participants had higher BFP values in all age groups (figure 1C). BMI reached its highest value for men in the 35-44 year age group and for men in the 55-64year age group (figure 1D). The SBP was similar between men and women in all age groups (figure 1E), 
Table 1 Distribution of participants by age and sex in Jilin province ( $N, \%)$

\begin{tabular}{|c|c|c|c|c|c|c|}
\hline \multirow[b]{2}{*}{ Age } & \multicolumn{2}{|l|}{ Male } & \multicolumn{2}{|c|}{ Female } & \multicolumn{2}{|l|}{ Total } \\
\hline & $\mathbf{N}$ & $\%$ & $\mathbf{N}$ & $\%$ & $\mathbf{N}$ & $\%$ \\
\hline $15-24$ & 1120 & 9.07 & 1146 & 8.51 & 2266 & 17.59 \\
\hline $35-44$ & 1084 & 11.95 & 1359 & 11.40 & 2443 & 23.35 \\
\hline $45-54$ & 1043 & 10.02 & 1333 & 9.68 & 2376 & 19.70 \\
\hline $65-74$ & 755 & 3.01 & 823 & 3.23 & 1578 & 6.24 \\
\hline $75+$ & 678 & 1.31 & 708 & 1.55 & 1386 & 2.86 \\
\hline Total & 6946 & 50.63 & 8010 & 49.37 & 14956 & 100.0 \\
\hline
\end{tabular}

although male participants had higher DBP values in all age groups (figure $1 \mathrm{~F}$ ).

The overall prevalence of overweight and obesity of participants was $29.8 \%$ and $6.2 \%$, respectively. Male participants had a higher prevalence of overweight than female participants $(30.9 \%$ vs $28.7 \%, \mathrm{p}=0.013)$. No statistical

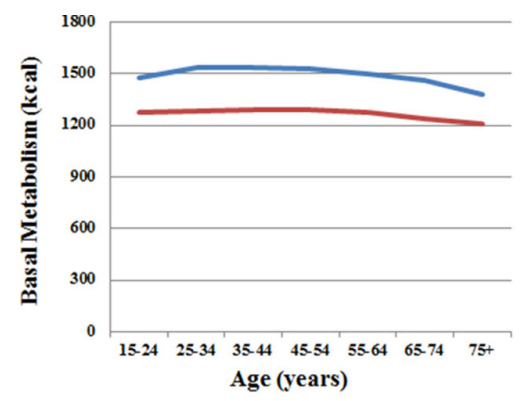

A

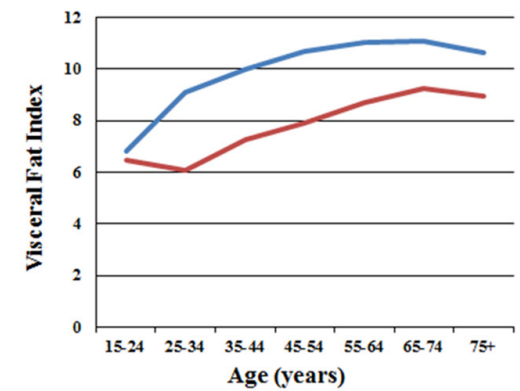

C

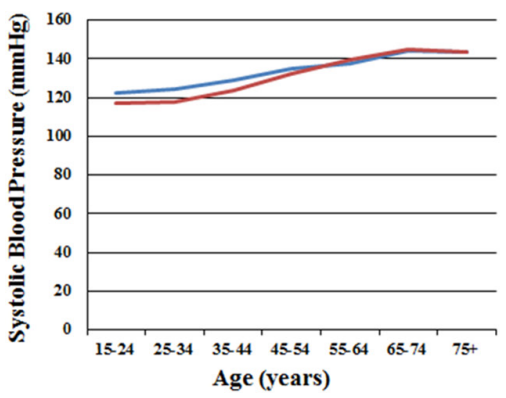

E
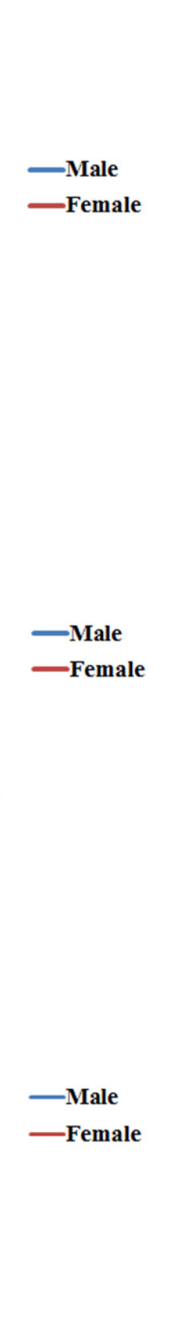

difference was observed in the prevalence of obesity among male and female participants $(6.3 \%$ vs $6.2 \%$, $\mathrm{p}=0.78)$. The overall percentages of current smoking and ever smoking were $22.7 \%$ and $1.4 \%$, respectively. When stratified by sex, the percentage of current smoking in men $(36.9 \%)$ was significantly higher than that in
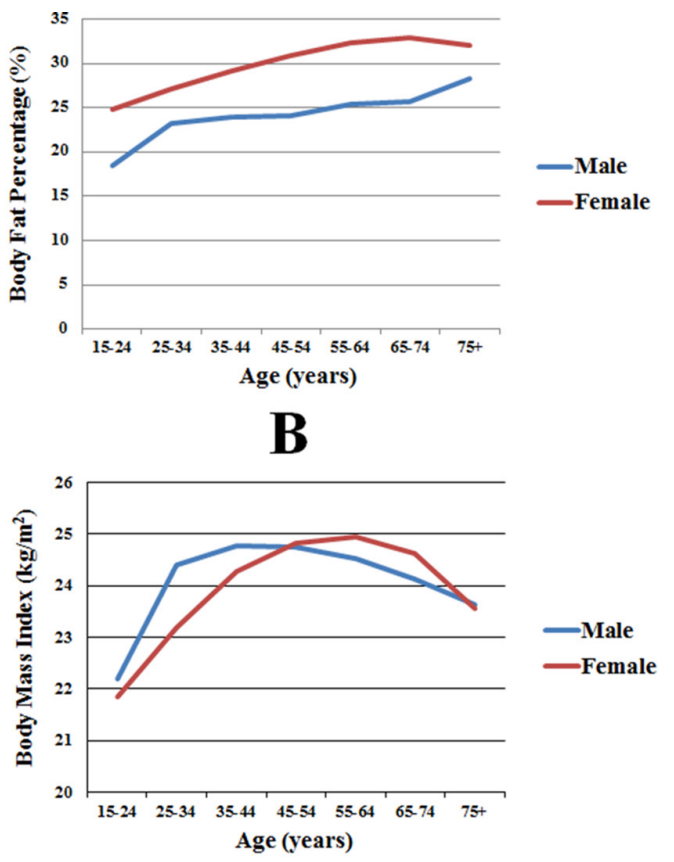

D

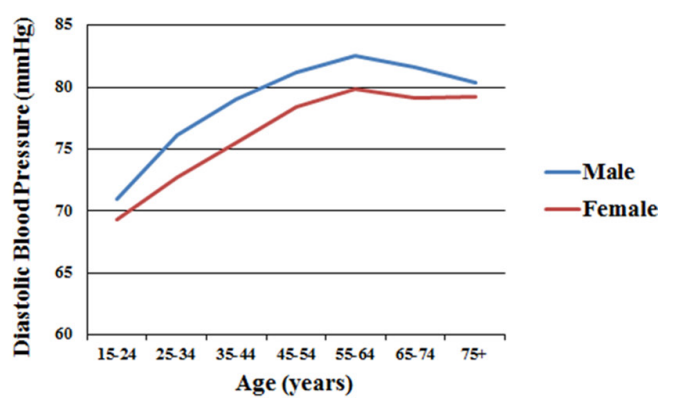

F

Figure 1 Trends of physical characteristics by age and sex. (A) basal metabolism; (B) body fat percentage; (C) visceral fat index; (D) body mass index; (E) systolic blood pressure; (F) diastolic blood pressure. 
women $(8.2 \%) \quad(p<0.001)$. Similarly, the percentage of ever smoking in men $(2.3 \%)$ was significantly higher than that in women $(0.5 \%) \quad(\mathrm{p}<0.001)$. The overall percentage of alcohol drinking was $17.6 \%$. The percentage in men $(32.0 \%)$ was significantly higher than in women $(2.9 \%)$ $(p<0.001)$. The risk factors BMI, smoking and alcohol drinking, summarised by age and sex are shown in table 2 .

\section{Prevalence of hypertension stratified by non-modifiable factors-age and sex}

Of the 14956 participants, 4332 were diagnosed with hypertension, and the prevalence of hypertension was $24.7 \%$ (95\% CI $23.9 \%$ to $25.5 \%$ ). The prevalence of hypertension increased as older ages and was higher in men $(25.6 \%)$ than in women $(23.8 \%)(\mathrm{p}=0.03)$. among the age groups under 45 years old, the prevalence of hypertension in men was significantly higher than in women $(p<0.001)$; while for the $65-74$ year age group, the prevalence of hypertension in women was higher than in men $(p=0.04)$; and in the other age groups, the prevalence of hypertension in males and females showed no statistical difference $(\mathrm{P}>0.05)$. The prevalences of hypertension stratified by age and sex are shown in table 3 .

\section{Prevalence of hypertension stratified by modifiable factors- obesity, smoking and alcohol drinking}

The prevalences of hypertension varied statistically between the BMI categories $(p<0.001)$; the highest prevalence being reported was $48.1 \%$ in the obese group, followed by the overweight group at $35.7 \%$. The prevalence of hypertension also verified significantly when stratified by smoking $(\mathrm{p}<0.001)$, with the highest prevalence of $53.1 \%$ in the ever smoking group, followed by $32.2 \%$ in the current smoking group and $22.0 \%$ in the never smoking group. The prevalence of hypertension was significantly higher in the alcohol drinking group than in the no-alcohol drinking group $(34.6 \%$ vs $22.6 \%$, $\mathrm{p}<0.001)$. The prevalence of hypertension stratified by BMI, smoking and alcohol drinking are shown in table 4 .

\section{Factors associated with hypertension}

Several factors, including age, sex, obesity, smoking and alcohol drinking are associated with the prevalence of hypertension, in both the crude model and the adjusted logistic model. In particular, the univariate logistic model indicated that the risk of hypertension was greater in males with an $\mathrm{OR}=1.1$ (95\% CI 1.01 to 1.2 ) than in females, overweight participants with an $\mathrm{OR}=2.52(95 \%$ CI: 2.3 to 2.77$)$ than in normal participants, obese participants with an $\mathrm{OR}=4.21$ (95\% CI: 3.56 to 4.96 ) than in normal participants, smokers with $\mathrm{OR}=1.64 \quad(95 \% \mathrm{CI}$ : 1.48 to 1.81 ) than in non-smokers, and alcohol drinkers with OR=1.81 (95\% CI: 1.62 to 2.02) than in non-alcohol drinkers. All the difference were statistically significant $(\mathrm{P}<0.05)$. After adjustment for age, sex, region, education level, employment status, BMI, family history of hypertension, and marital status that may affect hypertension, the risk of hypertension was greater in males with an adjusted
OR=1.26 (95\% CI:1.13 to 1.39$)$ than in females, in overweight participants with an adjusted OR=2.3 (95\% CI: 2.06 to 2.58 ) than in normal participants, in obese participants with an adjusted OR=5.11 (95\% CI: 4.16 to 6.27 ) than in normal participants, in smokers with an adjusted $\mathrm{OR}=1.28$ (95\% CI: 1.13 to 1.46$)$ than in non-smokers, and in alcohol drinkers with an adjusted $\mathrm{OR}=1.49$ (95\% CI: 1.28 to 1.73$)$. These results are shown in table 5 .

\section{DISCUSSION}

Based on an estimated prevalence of $24.7 \%$ for hypertension in Jilin province, approximately 6.8 million residents would be considered hypertensive. At the national level, the prevalence of hypertension in Jilin is comparable to that in Zhejiang province,${ }^{12}$ while the prevalence is lower than in other regions in China, including Jiangxi, ${ }^{13}$ Inner Mongolia ${ }^{14}$ and Macau, ${ }^{15}$ as well as, lower than the overall prevalence in China. ${ }^{16}$ At the global level, the prevalence in Jilin is lower than that in the US and the UK, but is higher than that in Canada. ${ }^{4}$ However, there are some limitations in terms of the direct comparisons among these studies, given the varying methods, environments, population genetics and population age structures.

Although the prevalence from the present study is lower than the prevalence form $2012(24.7 \%$ vs $30.8 \%),{ }^{17}$ it remains unacceptably high in terms of optimal hypertension health in the province. Our study found that the prevalence of overweight and obesity was $29.8 \%$ and $6.2 \%$, respectively, which is higher than that reported at the national level of $17.7 \%$ and $5.6 \%$, respectively. ${ }^{18}$ Several studies have shown that obesity is a risk factor for the development of hypertension. ${ }^{19-21}$ Obesity can increase hypertension through multiple mechanisms, including insulin resistance, activation of sympathetic nervous system, sodium retention leading to increased renal reabsorption and activation of the renin-angiotensin system. ${ }^{22}$ Thus, the increasing populations of overweight and obese Jilin residents suggests the potential risk of future increasing incidence of hypertension. Unfortunately, this modifiable risk factor has exhibited no change in between the report in 2012 and now, ${ }^{17}$ and the population of overweight and obesity may even be underestimated because the standard definitions for overweight and obesity used in our research may be too high for Asian population. ${ }^{23}$ Moreover, abdominal obesity can be present in individuals with normal BMI values $\left(18.5-24.9 \mathrm{~kg} / \mathrm{m}^{2}\right)$, and some studies have indicated that this condition could be a risk factor for hypertension. ${ }^{25}{ }^{26}$ Thus, as overweight and obesity are modifiable risk factors, effective proactive intervention programme could help slow and ultimately reduce the number of individuals with obesity becoming hypertensive.

Our study found that the overall prevalence of hypertension increased with age in both men and women, especially at ages of 35-74 years. This result supports the hypothesis that age is a risk factor for hypertension. ${ }^{27-30}$ An increasing lifespan among the population in Jilin 


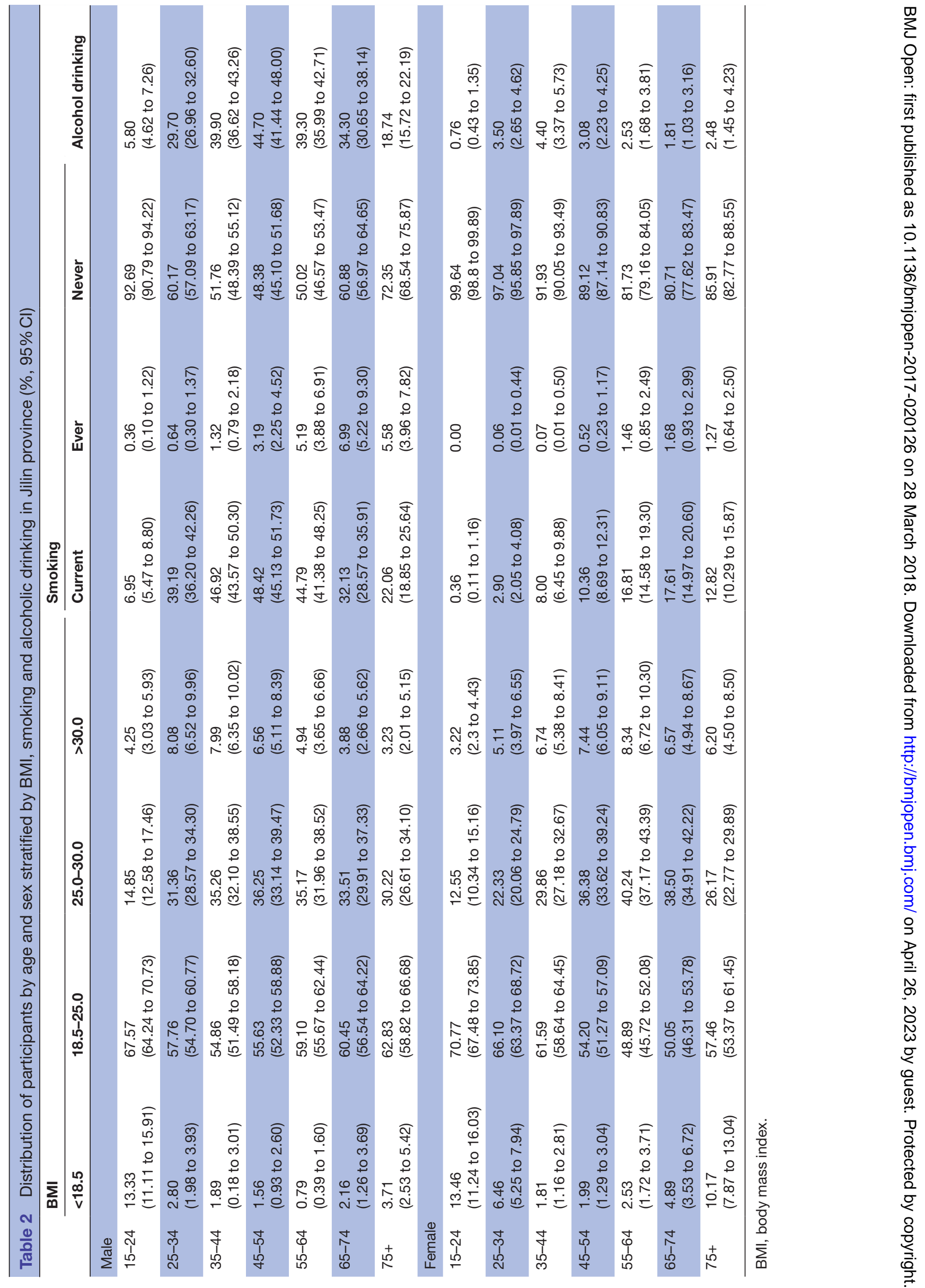


Table 3 Prevalence of hypertension by age and sex in Jilin province

\begin{tabular}{|c|c|c|c|c|c|c|}
\hline \multirow[b]{2}{*}{ Age group } & \multicolumn{2}{|l|}{ Male } & \multicolumn{2}{|c|}{ Female } & \multicolumn{2}{|l|}{ Total } \\
\hline & $\mathbf{N}$ & $\%(95 \% \mathrm{Cl})$ & $\mathbf{N}$ & $\%(95 \% \mathrm{Cl})$ & $\mathbf{N}$ & $\%(95 \% \mathrm{Cl})$ \\
\hline $15-24$ & 80 & 6.86 (5.27 to 8.87 ) & 23 & 1.88 (1.19 to 2.96$)$ & 103 & 4.45 (3.53 to 5.59 ) \\
\hline $35-44$ & 221 & 21.00 (18.36 to 23.91$)$ & 195 & $15.21(13.14$ to 17.55$)$ & 416 & 18.17 (16.45 to 20.03$)$ \\
\hline $45-54$ & 379 & 35.13 (32.06 to 38.33$)$ & 430 & 32.57 (29.89 to 35.36$)$ & 809 & 33.87 (31.82 to 35.99$)$ \\
\hline $65-74$ & 451 & 59.91 (55.98 to 63.71$)$ & 518 & 65.32 (61.72 to 68.76$)$ & 969 & 62.71 (60.06 to 65.29$)$ \\
\hline $75+$ & 405 & 61.24 (57.24 to 65.10$)$ & 449 & 62.37 (58.30 to 66.28$)$ & 854 & 61.86 (59.00 to 64.63$)$ \\
\hline Total & 2091 & 25.60 (24.41 to 26.79$)$ & 2241 & 23.84 (22.80 to 24.89$)$ & 4332 & 24.73 (23.94 to 25.53 ) \\
\hline
\end{tabular}

requires a practical and effective hypertension management strategy that targets its ageing population. The overall prevalence of hypertension was higher in men than in women. However, the prevalence in women increased more rapidly than in men aged 65-74 years. This may be partially explained by hormonal changes in postmenopausal women and the difference in lifespan between men and women. ${ }^{431}$ However, the exact mechanisms need to be explored.

Consistent with previous studies, ${ }^{32} 33$ our study also showed that smoking, both current and ever smoking, was associated with an increased risk of hypertension. Smoking can increase blood viscosity, stimulate the adrenergic nervous system and contribute to the development of both microvascular and macrovascular diseases. ${ }^{34}$ Although some studies reported weak associations between smoking and hypertension, ${ }^{1320}$ smoking is still considered a major risk factor worldwide ${ }^{.13} 2035-37$ Additionally, drinking of alcohol is also a risk factor for hypertension in our study, which is consistent with previous studies. ${ }^{48-40}$ These results indicate that some lifestyle changes, such as quitting smoking and reducing or stopping alcohol consumption, should help to reduce the prevalence of hypertension.

National studies reported that the prevalence of hypertension is higher in northern China than that in southern China. ${ }^{76}$ When comparing the associations between risk factors and hypertension with Zhejiang province located in the South, ${ }^{12}$ we found that the risk of hypertension with demographic factors, such as age, sex and region, and clinical factors, such as family history of hypertension and abdominal waist circumference, were similar in Jilin province and in southern China. When it comes to the lifestyle factors, the risk of hypertension with obesity and alcohol drinking were similar; however, there was a marked difference in the modifiable risk factor smoking; in particular, in Jilin province there was a strong association with an adjusted $\mathrm{OR}=1.28(95 \%$ CI 1.13 to 1.46$)$, whereas no association between smoking and hypertension in southern China was found, with an adjusted OR=1.0 (95\% CI 0.9 to 1.1$)$. These findings indicate that smoking cessation programmes could help mitigate the prevalence of hypertension in Jilin province. Some social factors including retirement status, marital status and education level were also different between the North and the South. Of interest, there was a difference on BFP categories. In particular, for categories 10-19 for men and 20-29 for women, there was no association between BFP and hypertension in Jilin province with an adjusted $\mathrm{OR}=0.95$ (95\% CI 0.71 to 1.27 ), whereas in this category $\mathrm{BFP}$ is protective against hypertension in south China with an adjusted OR=0.6 (95\% CI 0.5 to 0.8 ). In the range of over 25 for men and over 35 for women, BFP is strongly associated with hypertension in Jilin province with an adjusted OR=1.45 (95\% CI 1.07 to 1.96 ), whereas no association was found in the South with an adjusted OR=1.3 (95\% CI 1.0 to 1.5 ). These results indicate that BFP tends to be more of a risk for hypertension in the North compared with the South. High BFP values are associated with increased blood pressure, ${ }^{4142}$ and there may be ethnicity-based differences in the relationship between BFP and BMI. ${ }^{43}$ Those results may help explain the region-specific relationships between BFP and hypertension in northern and southern China, although further studies are needed to better understand these relationships.

A survey from 2012 found a prevalence of hypertension of $30.8 \% .{ }^{17}$ The prevalence of hypertension in our study was lower. This reduction may be related to the following two factors. First, the Jilin government is aware of the damage and burden of hypertension and has increased medical insurance funding (especially for rural residents), from RMB $¥ 3.9$ billion in 2012 to RMB $¥ 6.4$ billion in 2015 , according to the statistical bureau of Jilin province. Second, new hypertension guidelines for China were published since 2012, and these guidelines addressed the grassroots management of hypertension ${ }^{44}$ and patient education. ${ }^{45}$ However, some key modifiable risk factors have exhibited slight negative changes, in particular, the trend towards obesity, drinking and smoking. This can be due in part to the Jilin's growing economy, which has increased from a gross domestic product of RMB $¥ 361.5$ billion in 


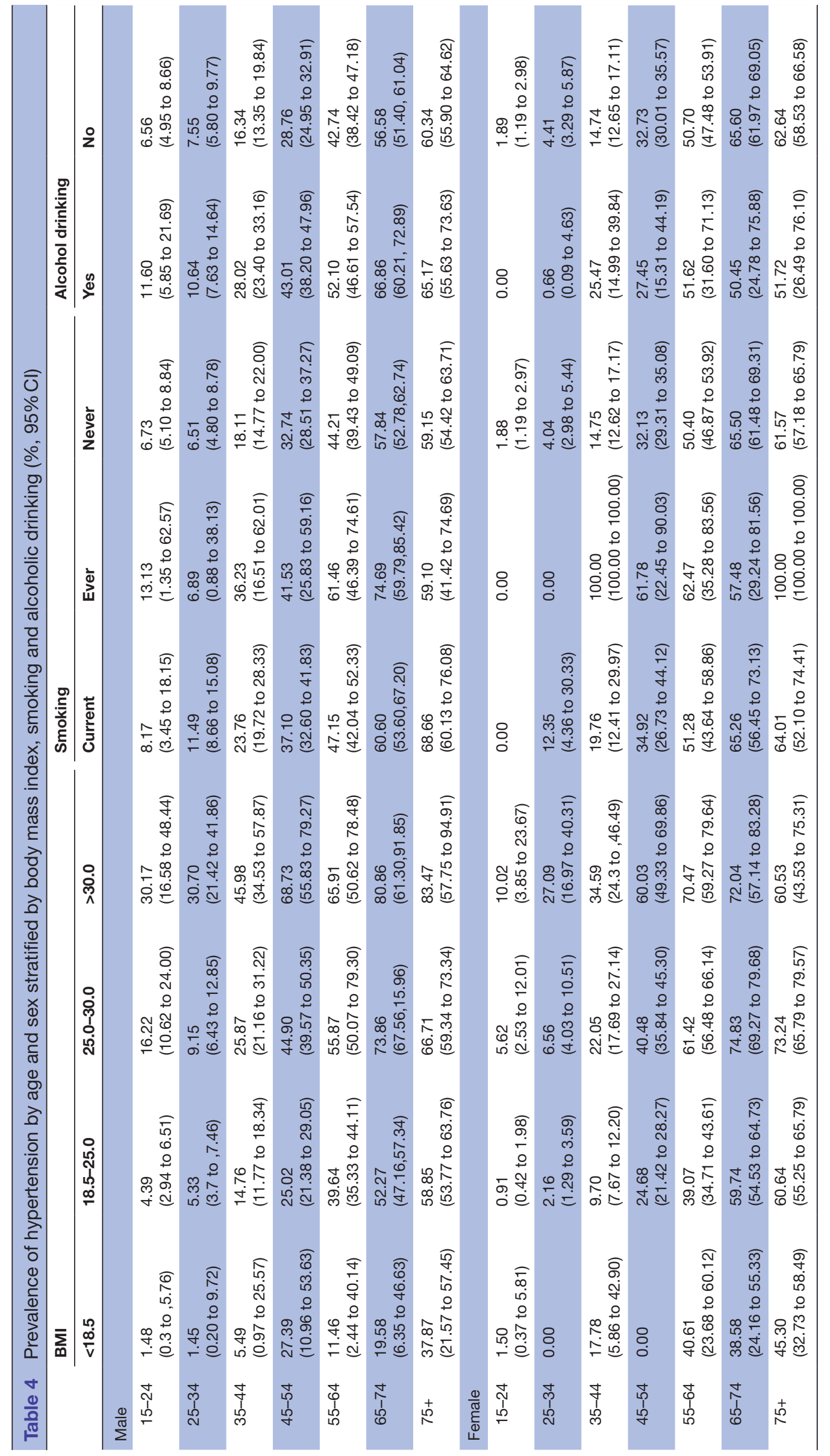


Table 5 Risk factors associated with the prevalence of hypertension

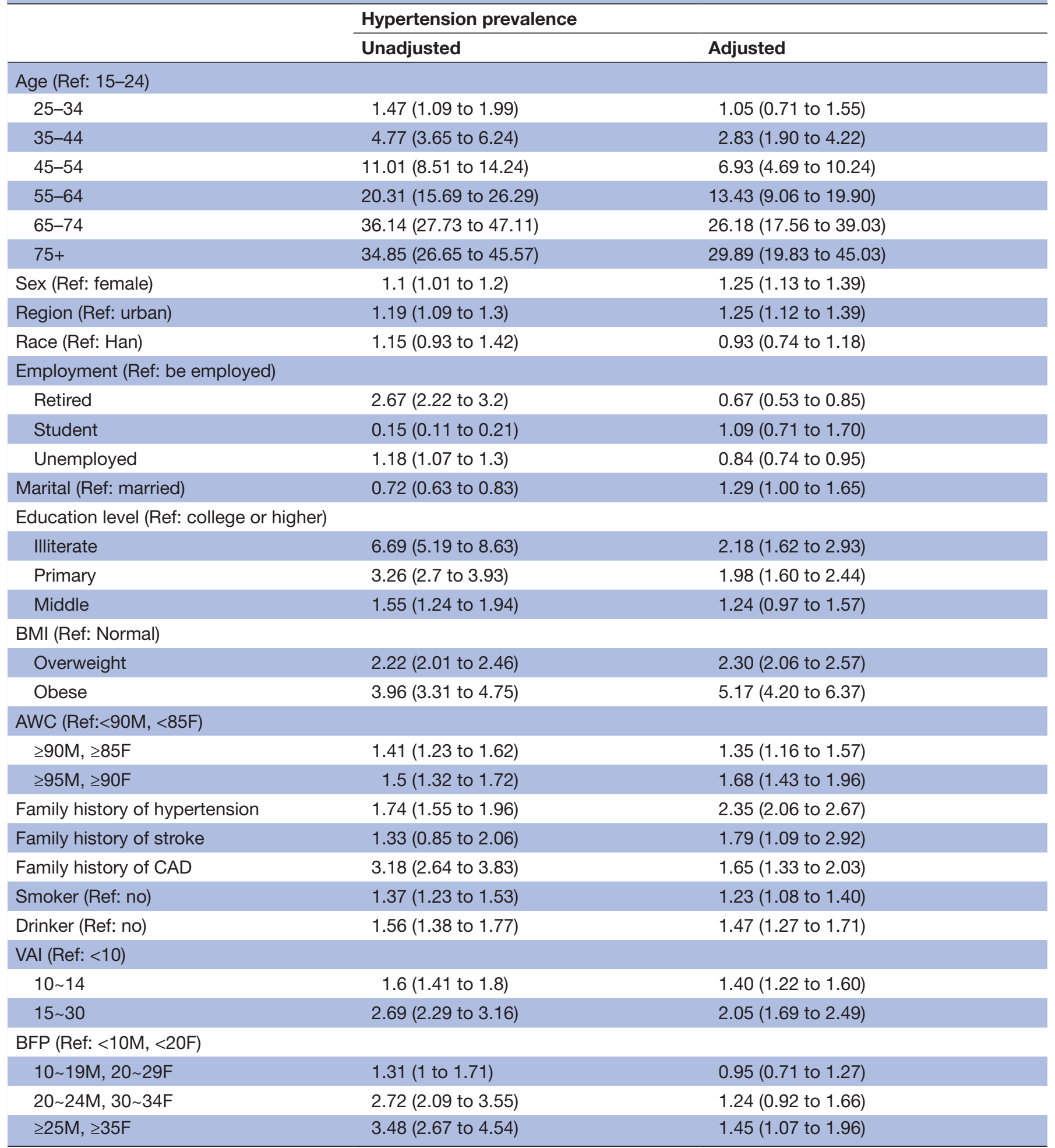

Adjusted for sex, region, age, education level, employment status, marital status, BMI and family history of hypertension. AWC, abdominal waist circumference; BFP, body fat percentage; BMI, body mass index; CAD, coronary heart disease; F, female; M, male; VAI, visceral fat.

1995 , to RMB ¥857.8 billion in 2010 , to RMB ¥1.4 trillion in 2015, according to the statistical bureau of Jilin province. To reverse these trends will require an effective and workable intervention programme to control hypertension by incorporating best practices identified in theory and practice. For example, rates of hypertension awareness have greatly improved from $24.4 \%$ to $42.6 \%$, and the treatment rates have improved from $20.0 \%$ to $24.2 \%$ based on national surveys. ${ }^{16}$ However, the control rate is only $9.3 \%$ in comparison with $53 \%$ 
in the USA. ${ }^{4}$ One of the challenges is to improve adherence to antihypertension drugs.

This study was a cross-sectional study and contained a large representative sample. These factors will allow for the generalisation of our findings to residents aged 15 years and over in northern China. However, there are some limitations in this study. First, this is a cross-sectional study design, thus the causality cannot be assumed between the risk factors and hypertension. Second, financial limitations precluded collection of data regarding physical activity, salt intake and blood lipid levels. Third, the decrease of prevalence of hypertension in our study compared with that in 2012 may be related with sampling factor.

In summary, the prevalence of hypertension in Jilin province decreased compared with that in 2012 and is lower than the overall prevalence in China. In addition, the study showed that hypertension was associated with age, sex, obesity, smoking and alcohol drinking. In particular, smoking may be responsible for the different prevalences of hypertension in northern and southern China. These factors above, especially smoking, will be important points to control and manage hypertension in Jilin province.

Contributors BL was involved in the study's design. JW, XS, LL, YY, YL and CQ collected the data. YZ and YL performed the statistical analysis. TL, WS and BL wrote the paper. All authors reviewed and approved the final version of the paper.

Funding This work was supported by the National Key R\&D Program in the Twelfth Five-year Plan (No. 2011BAl11B01) from the Chinese Ministry of Science and Technology and the National Clinical Key Specialty Project.

Competing interests None declared.

Patient consent Not required.

Ethics approval This study was approved by the Fuwai Hospital Ethics Review Board.

Provenance and peer review Not commissioned; externally peer reviewed.

Data sharing statement No additional data are available.

Open Access This is an Open Access article distributed in accordance with the Creative Commons Attribution Non Commercial (CC BY-NC 4.0) license, which permits others to distribute, remix, adapt, build upon this work non-commercially, and license their derivative works on different terms, provided the original work is properly cited and the use is non-commercial. See: http://creativecommons.org/ licenses/by-nc/4.0/

(C) Article author(s) (or their employer(s) unless otherwise stated in the text of the article) 2018. All rights reserved. No commercial use is permitted unless otherwise expressly granted.

\section{REFERENCES}

1. World Health Organization. Global action plan for the prevention and control of noncommunicable diseases 2013-2020, 2013.

2. Cifkova R, Fodor G, Wohlfahrt P. Changes in hypertension prevalence, awareness, treatment, and control in high-, middle-, and low-income countries: an update. Curr Hypertens Rep 2016;18:62.

3. Neuhauser HK, Adler C, Rosario AS, et al. Hypertension prevalence, awareness, treatment and control in Germany 1998 and 2008-11. J Hum Hypertens 2015;29:247-53.

4. Joffres M, Falaschetti E, Gillespie C, et al. Hypertension prevalence, awareness, treatment and control in national surveys from England, the USA and Canada, and correlation with stroke and ischaemic heart disease mortality: a cross-sectional study. BMJ Open 2013;3:e003423.
5. Wu X, Duan X, Gu D, et al. Prevalence of hypertension and its trends in Chinese populations. Int J Cardiol 1995;52:39-44.

6. Wu Y, Huxley R, Li L, et al. Prevalence, awareness, treatment, and control of hypertension in China: data from the China National Nutrition and Health Survey 2002. Circulation 2008;118:2679-86.

7. Reynolds K, Gu D, Muntner P, et al. Geographic variations in the prevalence, awareness, treatment and control of hypertension in China. J Hypertens 2003;21:1273-81.

8. Wang X, Bots ML, Yang F, et al. Prevalence of hypertension in China: a systematic review and meta-regression analysis of trends and regional differences. J Hypertens 2014;32:1919-27.

9. Wang Z, Zhang L, Chen Z, et al. China Hypertension Survey G: survey on prevalence of hypertension in China: background, aim, method and design. International journal of cardiology 2014:174:721-3.

10. Fodor JG, Leenen FH, Helis E, et al. 2006 Ontario Survey on the Prevalence and Control of Hypertension (ON-BP): rationale and design of a community-based cross-sectional survey. Can J Cardiol 2008;24:503-5

11. Lenfant $\mathrm{C}$, Chobanian $\mathrm{AV}$, Jones DW, et al. Seventh report of the joint national committee on the prevention, detection, evaluation, and treatment of high blood pressure (JNC 7): resetting the hypertension sails. Hypertension 2003;41:1178-9.

12. Yang L, Yan J, Tang X, et al. Control and risk factors associated with hypertension among adults in Southern China, 2013. PloS one 2016;11:e0146181.

13. Hu L, Huang $X$, You C, et al. Prevalence and risk factors of prehypertension and hypertension in Southern China. PLoS One 2017;12:e0170238.

14. Li G, Wang H, Wang K, et al. Prevalence, awareness, treatment, control and risk factors related to hypertension among urban adults in Inner Mongolia 2014: differences between Mongolian and Han populations. BMC Public Health 2016;16:294.

15. Ke L, Ho J, Feng J, et al. Prevalence, awareness, treatment and control of hypertension in Macau: results from a crosssectional epidemiological study in Macau, China. Am J Hypertens 2015;28:159-65.

16. Wang J, Zhang L, Wang F, et al. China National Survey of Chronic Kidney Disease Working G: prevalence, awareness, treatment, and control of hypertension in China: results from a national survey. Am J Hypertens 2014;27:1355-61.

17. Yang G, Ma Y, Wang S, et al. Prevalence and correlates of prehypertension and hypertension among adults in northeastern china: a cross-sectional study. Int J Environ Res Public Health $2015 ; 13: 82$

18. Li LM, Rao KQ, Kong LZ, et al. [A description on the Chinese national nutrition and health survey in 2002]. Zhonghua Liu Xing Bing Xue Za Zhi 2005;26:478-84.

19. Crump C, Sundquist J, Winkleby MA, et al. Interactive effects of physical fitness and body mass index on the risk of hypertension. JAMA Intern Med 2016;176:210-6.

20. Papathanasiou G, Zerva E, Zacharis I, et al. Association of high blood pressure with body mass index, smoking and physical activity in healthy young adults. Open Cardiovasc Med J 2015;9:5-17.

21. Tyson CC, Appel LJ, Vollmer WM, et al. Impact of 5-year weight change on blood pressure: results from the Weight Loss Maintenance trial. J Clin Hypertens 2013;15:458-64.

22. Rahmouni K, Correia ML, Haynes WG, et al. Obesity-associated hypertension: new insights into mechanisms. Hypertension 2005;45:9-14.

23. World Health Organization. The Asia-Pacific perspective: redefining obesity and its treatment. Sydney: Health Communications Australia, 2000.

24. Anuurad E, Shiwaku K, Nogi A, et al. The new BMI criteria for asians by the regional office for the western pacific region of WHO are suitable for screening of overweight to prevent metabolic syndrome in elder Japanese workers. $J$ Occup Health 2003:45:335-43.

25. Okosun IS, Prewitt TE, Cooper RS. Abdominal obesity in the United States: prevalence and attributable risk of hypertension. J Hum Hypertens 1999;13:425-30.

26. Bergman RN, Kim SP, Hsu IR, et al. Abdominal obesity: role in the pathophysiology of metabolic disease and cardiovascular risk. Am J Med 2007;120:S3-S8.

27. Yang $L, X u X$, Yan J, et al. Analysis on associated factors of uncontrolled hypertension among elderly hypertensive patients in Southern China: a community-based, cross-sectional survey. BMC Public Health 2014;14:903.

28. Yip W, Wong TY, Jonas JB, et al. Prevalence, awareness, and control of hypertension among Asian Indians living in urban Singapore and rural India. J Hypertens 2013;31:1539-46. 
29. Doulougou B, Gomez F, Alvarado B, et al. Factors associated with hypertension prevalence, awareness, treatment and control among participants in the International Mobility in Aging Study (IMIAS). $J$ Hum Hypertens 2016;30:112-9.

30. Cheng S, Xanthakis V, Sullivan LM, et al. Blood pressure tracking over the adult life course. Hypertension 2012:112.201780.

31. Guo X, Zheng L, Li Y, et al. Gender-specific prevalence and associated risk factors of prehypertension among rural children and adolescents in Northeast China: a cross-sectional study. Eur J Pediatr 2013;172:223-30.

32. Bhadoria AS, Kasar PK, Toppo NA, et al. Prevalence of hypertension and associated cardiovascular risk factors in Central India. J Family Community Med 2014;21:29.

33. Malekzadeh MM, Etemadi A, Kamangar F, et al. Prevalence, awareness and risk factors of hypertension in a large cohort of Iranian adult population. $J$ Hypertens 2013;31:1364-71.

34. Heitmar R, Summers RJ. Assessing vascular function using dynamic retinal diameter measurements: a new insight on the endothelium. Thromb Haemost 2012;107:1019-26.

35. Meng XJ, Dong GH, Wang D, et al. Prevalence, awareness, treatment, control, and risk factors associated with hypertension in urban adults from 33 communities of China: the CHPSNE study. $J$ Hypertens 2011;29:1303-10.

36. Pereira M, Lunet N, Azevedo A, et al. Differences in prevalence, awareness, treatment and control of hypertension between developing and developed countries. $J$ Hypertens 2009;27:963-75
37. Bowman TS, Gaziano JM, Buring JE, et al. A prospective study of cigarette smoking and risk of incident hypertension in women. J Am Coll Cardiol 2007;50:2085-92.

38. Stranges S, Wu T, Dorn JM, et al. Relationship of alcohol drinking pattern to risk of hypertension: a population-based study. Hypertension 2004;44:813-9.

39. Grucza RA, Krueger RF, Racette SB, et al. The emerging link between alcoholism risk and obesity in the United States. Arch Gen Psychiatry 2010;67:1301-8.

40. Ke L, Ho J, Feng J, et al. Modifiable risk factors including sunlight exposure and fish consumption are associated with risk of hypertension in a large representative population from Macau. $J$ Steroid Biochem Mol Biol 2014;144 Pt A:152-5.

41. Shea JL, King MT, Yi Y, et al. Body fat percentage is associated with cardiometabolic dysregulation in BMI-defined normal weight subjects. Nutr Metab Cardiovasc Dis 2012;22:741-7.

42. Weinsier RL, Norris DJ, Birch R, et al. The relative contribution of body fat and fat pattern to blood pressure level. Hypertension 1985;7:578-85

43. Barba C, Cavalli-Sforza T, Cutter J, et al. Appropriate body-mass index for Asian populations and its implications for policy and intervention strategies. Lancet 2004;363:157.

44. Wang W. Guidelines for the management of hypertension in China. Chinese Journal of Hypertension 2015;23:24-43.

45. Wu Z, Yong $\mathrm{H}$, Wang W, et al. Guidelines for hypertension education in China. Chinese Journal of Hypertension 2014;3:78-110. 